\title{
PARTISIPASI KELOMPOK PECINTA ALAM FORESTER TAPANULI BAGIAN SELATAN DALAM PELESTARIAN ORANGUTAN SUMATERA (PONGO ABELII) DI CAGAR ALAM DOLOK SIBUAL-BUALI KABUPATEN TAPANULI SELATAN
}

\author{
Safran Efendi Pasaribu(1) dan Rizki Efendi Harahap ${ }^{(2)}$ \\ ${ }^{(1)}$ Dosen FKIP Univeristas Muhammadiyah Tapanuli Selatan \\ (2) Anggota Kelompok Pecinta Alam Forester Tabagsel
}

\begin{abstract}
Abstrak
Habitat Orangutan Sumatera (Pongo Abelli) pada dasarnya memiliki manfaat jasa lingkungan yang secara tidak langsung bernilai guna untuk mendukung kebutuhan dan kehidupan manusia. Menjaga habitat orangutan berarti turut serta melindungi hutan yang memiliki beragam manfaat yang dapat dijadikan sebagai sumber dana bagi kegiatan konservasi. Tujuan penelitian ini adalah untuk mengetahui partisipasi Kelompok Pecinta Alam Forester Tapanuli Bagian Selatan dalam pelestarian Orangutan Sumatera (Pongo Abelli) dan kendala yang dihadapi Kelompok Pecinta Alam Forester Tapanuli Bagian Selatan dalam berpatisipasi melestarikan Orangutan Sumatera (Pongo Abelli) di Cagar Alam Dolok Sibual-buali Kabupaten Tapanuli Selatan. Metode yang digunakan dalam penelitian ini adalah metode penelitian deskriptif dengan meggunakan pendekatan kualitatif, Pengumpulan data dilakukan dengan melakukan wawancara dengan responden secara langsung. Dari hasil penelitian yang dilakukan penulis, Partisipasi Kelompok Pecinta Alam Forester Tapanuli Bagian Selatan Dalam Pelestarian Orangutan Sumatera (Pongo Abelli) belum cukup optimal, karena disamping terbatasnya pendanaan untuk kegiatan konservasi orangutan, peran Pemerintah, swasta, stakeholders dan masyarakat masih kurang peduli terhadap kelestarian hutan, Dengan tujuan kepentingan perekonomian. Untuk itu diperlukan campur tangan pemerintah, swasta, dan stakeholders untuk mengajak lembaga lokal dan masyarakat setempat dalam mengelola kawasan konservasi beserta keanekaragaman hayati guna terciptanya hutan yang lestari.
\end{abstract}

Kata Kunci: Orangutan Sumatera, Pecinta Alam, Tapanuli Selatan

\section{Pendahuluan}

Negara Indonesia memiliki sumber daya alam yang sangat berlimpah, dengan demikian negara Indonesia memiliki potensi lingkungan yang sangat besar untuk dikembangkan sebagai sarana mencari pengetahuan lebih lanjut. Bukan hanya itu, Indonesia juga merupakan salah satu paru- paru dunia yang terkenal kaya akan ragam flora dan faunanya, dapat disimpulkan sepertiga kekayaan alam dunia terdapat pada alam Indonesia.

Melestarikan lingkungan hidup merupakan kebutuhan yang tidak bisa ditunda lagi dan bukan hanya menjadi tanggung jawab pemerintah atau pemimpin 
negara saja, melainkan tanggung jawab setiap insan di bumi. Setiap orang harus melakukan usaha untuk menyelamatkan lingkungan hidup di sekitar kita sesuai dengan kapasitasnya masing-masing. Sekecil apa pun usaha yang kita lakukan sangat besar manfaatnya bagi terwujudnya bumi yang layak huni bagi generasi anak cucu kita kelak.

Pada umumnya organisasi merupakan suatu wadah yang bertumpu pada pengembangan masyarakat sesuai dengan tujuan yang ditetapkan bersama. Organisasi pecinta alam merupakan organisasi masyarakat yang berada di tengah masyarakat atas kehendak dan keinginan sendiri berusaha menampung dan menyalurkan aspirasinya dalam bidang cinta alam dan lingkungan hidup.

Kelompok pencinta alam lebih dikenal dalam lingkungan generasi muda khususnya para pelajar dan mahasiswa. Melalui wadah tersebut, mereka melakukan kegiatan rekreasi dan mencari tantangan atau petualangan di alam bebas, kegiatan tersebut biasanya dilakukan pada hari-hari libur atau libur semester.

Perkumpulan para pecinta alam alam tersebut kemudian disebut dengan Kelompok Pecinta Alam yang sebagian besar anggotanya dari kaum generasi muda yang tuimbuh dan berkembang secara swadaya dengan aktivitas yang berbedabeda.

Salah satu bagian dari kegiatan pembangunan konservasi sumber daya alam dan ekosistemnya adalah pengelolaan dan pemanfaatan sumberdaya alam dan ekosistemnya secara lestari dan berkesinambungan. Melalui kegiatan Cinta Alam diharapkan masyarakat akan lebih mengerti manfaat dan arti pelestarian sumber daya alam dan ekositemnya.
Organisasi Kelompok Pecinta Alam Forester Tapanuli Bagian Selatan adalah organisasi yang bergerak dibidang cinta alam dan lingkungan hidup dengan sifat independen dan non politik. Organisasi ini berdomisili di Kota Padangsidimpuan dengan ruang kerja di wilayah Tapanuli Bagian Selatan (Kabupaten Tapanuli Selatan, Padang Lawas, Padang Lawas Utara, Mandailing Natal dan Kota Padangsidimpuan). Kelompok Pecinta Alam Forester Tapanuli Bagian Selatan berdiri pada tanggal 01 Desember 2011 di Kota Padangsidimpuan yang digagas oleh 11 (sebelas) pemuda. Organisasi ini juga lebih menekankan pada kegiatan konservasi, pencarian pengetahuan dan wawasan baru, serta dapat lebih dekat mengetahui tentang fenomena alam dan lingkungan khususnya di wilayah Tapanuli Bagian Selatan.

Undang Undang Nomor 5 Tahun 2009 menyimpulkan sebagai berikut : Cagar alam adalah kawasan suaka alam karena keadaan alamnya mempunyai kekhasan tumbuhan, satwa, dan ekosistemnya atau ekosistem tertentu yang perlu dilindungi dan perkembangannya berlangsung secara alami.

Kawasan konservasi Cagar Alam Dolok Sibual-buali secara administrasi pemerintah terletak di 3 (tiga) wilayah kecamatan yaitu Kecamatan Sipirok, Kecamatan Angkola Timur, dan Kecamatan Marancar Kabupaten Tapanuli Selatan Provinsi Sumatera Utara, dengan pengelolaan pada wilayah kerja Seksi Konservasi wilayah IV, Bidang Konservasi Sumber Daya Alam (KSDA) Wilayah II Padangsidimpuan, Balai Konservasi Sumber Daya Alam Sumatera Utara.

Cagar Alam Dolok Sibual-buali secara geografis terletak pada kokordinat $01^{0} 0^{\prime}-01^{0} 37^{\prime}$ Lintang Utara dan $99^{\circ} 11^{\prime} 15^{\prime}$ ' Bujur Timur. Cagar Alam Dolok Sibualbuali terletak pada Daerah Aliran Sungai 
(DAS) Barumun. Cagar Alam Dolok Sibualbuali memiliki beberapa jenis satwa lindung yang terancam punah seperti, Orangutan Sumatera (Pongo Abelii) atau Mawas yang sering disebut orang di Tapanuli, Siamang (Hylobates Sindactylus), Kambing Hutan (Capricornis Sumatrensis), Harimau Sumatera (Panthera Tigris Sumatrensis), dll. (Balai Besar KSDA Sumut, Buku Informasi Kawasan Konservasi, Kemenhut : 2011)

\section{Orangutan Sumatera dengan} keunikan dan perbedaan genetika yang ada merupakan satwa kebanggaan daerah Tapanuli, sudah seharusnya kita masyarakat di Tapanuli turut menjaga dan melindungi habitatnya. Sebab Orangutan Sumatera adalah satwa endemik Sumatera, satwa yang hanya ada hidup di pulau Sumatera saja.

Satwa ini adalah satu dari tiga jenis kera besar cerdas, berdasarkan observasi tentang perilaku Orangutan Sumatera yang pernah dilakukan bahwa Orangutan Sumatera menggunakan alat untuk makan, satwa ini mematahkan cabang pohon, menyingkirkan ranting-rantingnya lalu mengasah ujungnya, lalu ia menggunakan cabang pohon itu untuk mencungkil lubang pohon untuk mencari rayap. Mereka juga menggunakan cabang pohon itu untuk memukul-mukul dinding sarang lebah serta menggunakan sehelai daun untuk menutupi wajahnya dari sengatan lebah, sungguh satwa yang sangat cerdas.

Dalam hal pelestarian satwa ini dan penjagaan Hutan Konservasi Cagar Alam Dolok Sibual-buali beserta isinya tidak bisa sepenuhnya ditangani oleh pemerintah saja selaku pihak yang berwenang, masih sangat dibutuhkan adanya keterlibatan aktif dari masyarakat sekitar kawasan ataupun organisasi yang bergerak dibidang lingkungan.
Dari observasi yang pernah dilakukan juga di kawasan Hutan Konservasi Cagar alam Dolok Sibual-buali telah terjadi beberapa kejadian pengrusakan lingkungan seperti : penebangan hutan, pencurian jenis tumbuhan, pemburuan satwa lindung bahkan konflik satwa-manusia, yaitu konflik dimana satu satwa telah dikasari oleh ulah tangan manusia secara langsung seperti : pemburuan satwa lindung Orangutan Sumatera, perlakuan yang tidak baik kepada Orangutan Sumatera dengan cara dilempari, Orangutan Sumatera yang keluar dari hutan dan masuk ke perkebunan warga memakan ataupun bersarang di pohon kebun warga, bahkan diburu dengan sengaja guna dibuat sajian (tambul) pada warungwarung tuak.

Hal ini diakibatkan kurangnya sosialisasi kepada masyarakat khususnya masyarakat sekitar kawasan hutan konservasi tersebut serta tak luput kurangnya partisipasi dari pihak organisasi yang bergerak dibidang lingkungan akan pentingnya penjagaan satwa langka yang terancam punah yaitu Orangutan Sumatera.

Berdasarkan latar belakang di atas, maka rumusan masalah yang akan diteliti dan dibahas adalah sebagai berikut :

1. Bagaimana partisipasi Kelompok Pecinta Alam Forester Tapanuli Bagian Selatan dalam pelestarian Orangutan Sumatera (Pongo Abelii) di Cagar Alam Dolok Sibual-buali Kabupaten Tapanuli Selatan?

2.Apa saja kendala yang dihadapi oleh Kelompok Pecinta Alam Forester Tapanuli Bagian Selatan dalam berpartisipasi melestarikan Orangutan Sumatera (Pongo Abelii) di Cagar Alam Dolok Sibual-buali Kabupaten Tapanuli Selatan? 


\section{Metode Penelitian}

Penelitian ini dilakukan di Kantor Sekretariat Kelompok Pecinta Alam Forester Tapanuli Bagian Selatan yang beralamat di J1. H. T. Rizal Nurdin Km.7 Gg. Jamalayu Lubis, Padangsidimpuan, Sumatera Utara Indonesia. Penelitian ini merupakan penelitian deskriptif, teknik pengumpulan datanya berupa studi kepustakaan dan studi lapangan. Penelitian ini berupaya untuk mengetahui partisipasi Kelompok Pecinta Alam Forester Tapanuli Bagian Selatan dalam melestarikan Orangutan Sumatera (Pongo Abelii) di Cagar Alam Dolok Sibualbuali Kabupaten Tapanuli Selatan sehingga menghasilkan data deskriptif berupa katakata tertulis atau lisan

\section{Pembahasan dan Hasil}

Perlindungan habitat bertujuan untuk melindungi, memelihara, mempertahankan, dan mengamankan habitat orangutan sehingga daya dukung kawasan meningkat dan populasinya berkembang secara alami. Habitat ideal bagi orangutan berupa hutan primer dengan ketersediaan pohon pakan yang cukup dan terbebas dari berbagai ancaman manusia.

Hasil analisis pendugaan daya dukung habitat, seperti "di CA Dolok Sibual-buali dapat mendukung populasi orangutan sekitar 47-56 individu, sedangkan populasinya masih di bawah 30 individu" (Kuswanda.W dan Sugiarti : 2016) Kondisi ini menunjukkan bahwa jumlah populasi yang ada saat ini dapat lebih meningkat bila keadaan kawasan dapat dilindungi lebih optimal. Rendahnya reproduksi dan perkembangan populasi orangutan mungkin lebih banyak disebabkan karena faktor gangguan terhadap habitatnya, terutama dari aktivitas masyarakat yang sering memasuki habitat orangutan, seperti pengambilan kayu bakar, air nira, dan perambahan lahan.

Rekonstruksi batas kawasan juga diperlukan karena beberapa tanda/pal batas telah rusak/hilang, tergeser atau dipindahkan, seperti di bagian Utara CA. Dolok Sibual-buali. Rekonstruksi tata batas dapat dilaksanakan minimal lima tahun sekali guna memberikan jaminan mengenai kejelasan posisi dan tanda batas dari hutan konservasi. Program selanjutnya yang harus terus dikembangkan adalah pemeliharaan pal batas untuk mempertegas batas serta meningkatkan pengawasan dan pengamanan kawasan. Kegiatan pemeliharaan dilaksanakan paling tidak 2-3 tahun sekali untuk mengganti pal yang rusak atau hilang dan memperjelas identitas pal yang sudah pudar.

Pada masa mendatang, penguatan kelembagaan perlu disinkronkan dengan program/pola pengelolaan hutan berbasis Kesatuan Pengelolaan Hutan (KPH) yang mencakup keseluruhan kawasan bentang alam Hutan Batang Toru, termasuk CA. Dolok Sibual-buali. Bentuk kelembagaan ini sebagai KPH Konservasi (KPHK) model yang mencakup pengelolaan fungsi produksi, lindung, dan konservasi.

Pengamanan di dalam dan sekitar hutan konservasi untuk menjaga keutuhan hutan konservasi harus dilakukan secara periodik. Namun harus disadari, terdapatnya keterbatasan SDM dan dana operasional sering berakibat pengamanan kawasan sulit 
dilakukan secara berkesinambungan. Di sisi lain, aktivitas pelanggaran dan ancaman terhadap keutuhan kawasan semakin hari semakin meningkat sehingga banyak hutan konservasi yang telah terdegradasi.

Selain itu, upaya peningkatan penegakan hukum dapat dilakukan melalui penyelenggaraan pelatihan bagi petugas dan anggota komunitas masyarakat (Pamhut Swakarsa), pelengkapan prasarana pengamanan bagi petugas dan masyarakat, dan peningkatan pengetahuan aparat penegak hukum tentang identifikasi satwa dilindungi dan aturan hukum yang mengaturnya.

Pembinaan habitat di kawasan SA Lubuk Raya dapat dilakukan untuk memulihkan kembali habitat terdegradasi melalui kegiatan rehabilitasi dan pengayaan tanaman, termasuk pada lahan yang sudah dikelola oleh masyarakat. Pelaksanaan program pembinaan habitat pada kawasan yang kritis diharapkan dapat menjadi habitat baru yang mampu mendukung pertumbuhan populasi orangutan dan memperbaiki proses dan fungsi ekosistem. Jenis tanaman yang berfungsi sebagai sumber pakan orangutan dapat menjadi prioritas dalam pemilihan jenis tanaman untuk mempercepat peningkatan daya hukung habitat bagi orangutan Sumatera.

\section{Kesimpulan}

Berdasarkan hasil penelitian dan pembahasan yang penulis lakukan, maka dapat diperoleh kesimpulan sebagai berikut

1. Partisipasi Kelompok Pecinta Alam Forester Tapanuli Bagian Selatan berbentuk aksi nyata yang terjun langsung lapangan dan ke masyarakat dengan melakukan pengawasan kawasan konservasi secara rutin, melakukan sosialisasi satwa lindung maupun riset populasi Orangutan Sumatera.

2. Kendala Kelompok Pecinta Alam Forester Tapanuli Bagian Selatan dalam berpartisipasi melestarikan Orangutan Sumatera (Pongo Abelii) di Cagar Alam Dolok Sibual-buali berupa pendanaan yang minim, kurangnya sumber daya manusia yang peduli akan kelestarian Orangutan Sumatera, serta pelaksanaan sanksi hukum kepada pelaku pengrusak habitat Orangutan Sumatera belum maksimal.

\section{Saran}

Saran yang diberikan penulis terkait dalam penelitian ini adalah :

1. Perlu adanya pembangunan fasilitas seperti pembuatan pos pemantauan Orangutan Sumatera, pembangunan stasiun riset dan karantina satwa agar tercapainya kawasan konservasi dan habitat Orangutan Sumatera yang lestari.

2. Perlu adanya perhatian khusus dari pemerintah kepada organisasi pecinta alam dengan 
memfasilitasinya atapun

memberikan bantuan dana guna kerja sama yang baik demi tercapainya kondisi hutan yang lestari.

3. Pengelolaan kawasan konservasi dalam melestarikan Orangutan Sumatera perlu campur tangan pemerintah secara optimal, dengan tetap melalui masyarakat setempat, serta organisasi pecinta alam sehingga dalam pengelolaannya untuk pelestarian Orangutan Sumatera yang berkelanjutan.

4. Bagi Kelompok Pecinta Alam Forester Tapanuli Bagian Selatan, perlu kiranya adanya pembentukan desa-desa konservasi yang ada di sekitar kawasan konservasi untuk memajukan pemahaman, pengetahuan maupun perekonomian masyarakat.

5. Dalam pengelolaan kawasan konservasi, perlu kiranya Kelompok Pecinta Alam Forester Tapanuli Bagian Selatan menjalin kerjasama dengan stakeholders untuk pelestarian Orangutan Sumatera, khususnya perusahaan-perusahaan yang ada di sekitar kawasan.

6. Mempertahankan dan lebih menegaskan akan adat dan budaya yang dianut oleh masyarakat sekitar sehingga terciptanya kerjasama yang baik antara organisasi pemerhati lingkungan dengan masyarakat di pinggir kawasan.

\section{Daftar Pustaka}

Alikodra. H.S, 1990. Pengelolaan SatwaLiar Jilid 1. Pusat Antar Universitas Ilmu Hayati IPB, Bogor. Direktorat Jenderal Pendidikan Tinggi Departemen Pendidikan dan Kebudayaan

Balai Besar KSDA Sumatera Utara, 2011, Buku Informasi Kawasan Konservasi, Medan : Kementerian Kehutanan.

Bambang Prasetyo dan Lina M. Jannah, 2005, Metode Penelitian Kualitatif, Jakarta : Rajawali Pers

Departemen Kehutanan, 2004. Peraturan Menteri Kehutanan Nomor P.19/Menhut-II/2004 tentang Pengelolaan Kolaboratif: Jakarta.

Fredriksson G.M dan G. Usher, 2013, Menuju Pengelolaan Lestari Hutan Batang Toru, Medan : Yayasan Ekosistem Lestari.

Irawan, Soehartono, 2008, Metode Penelitian Sosial, Bandung : Rosda

Kamus Besar Bahasa Indonesia/pengertian pelestarian.

Masli, Singarimbun, 2007, Metode Penelitian Survey, Jakarta : LP3ES

Suharsimi, Arikunto, 2002, Prosedur Penelitian Pendekatan Suatu Praktek, Jakarta : Rineka Cipta 
UNESCO-PanEco-Yayasan

Ekosistem Lestari (YEL), 2009, Cara Kerja

Survei Sebaran \& Populasi Orangutan DI

TNGL 2009-2010: Medan, Untuk Kalangan Sendiri.

Wanda Kuswanda, 18 April 2016.Status Terkini Populasi dan Ancaman Fragmentasi Habitat Orangutan di Kawasan Hutan Batang Toru. Proseding Hasil Seminar Lokakarya Para Pihak "Inisiasi Pengembangan Koridor Satwa di Bentang Alam Hutan se Tapanuli Bagian Selatan" Padangsidimpuan,

Wanda Kusmanda, 2014, Orangutan Batang Toru Kritis Diambang Punah, Jawa Barat, Forda Press

Wanda Kusmanda, 2007, Threats to The Population of Sumatera Orangutans (Pongo Abelli), Balai Penelitian Kehutanan Aek Nauli.

Wanda Kuswanda dan Sugiarti, 2005. Aktivitas Harian Orangutan Liar (Pongo Abelii Lesson 1827) di Cagar Alam Dolok Sibual-buali. Jurnal Penelitian Hutan dan Konservasi Alam: Bogor, Departemen Kehutanan.

Kuswanda.W dan Sukmana, 2009. Kesesuaian Jenis Untuk Pengkayaan Habitat Orangutan Terdegradasi di Daerah Penyangga Cagar Alam Dolok Sibual-buali. Jurnal Penelitian Hutan dan Konservasi Alam: Bogor. Departemen Kehutanan

Wanda Kuswanda, M. Bismark dan S. Iskandar. 2008. Analisis Habitat Lokasi
Pelepasliaran Orangutan (Pongo sp). Proseding Ekspose Hasil-hasil Penelitian "Peran Penelitian dalam Pelestarian dan Pemanfaatan Potensi Sumber daya Hutan di Sumatera Bagian Utara”. Pusat Pelatihan dan Pengembangan Hutan dan Konservasi Alam. Medan. 